\title{
17. Tutoring Systems and Computer-Assisted Language Learning (CALL)
}

\author{
Henning Lobin and Dietmar Rösler
}

\section{Introduction 1}

The steady increase in access to computers in educational settings has enhanced the possibilities for learners and teachers to engage in meaningful interaction in foreign language classrooms and has changed the shape of linguistic material used for learning purposes in ways that are both productive and problematic. Given the relatively recent emergence of digital media, it is fascinating to observe the speed of the development of the use of digital media in foreign language learning both on the level of the interaction between users and computers (from early stand alone CALL exercises to sophisticated online learning environments and data driven learning) and on the level of computer mediated interaction between humans (from early email exchanges to sophisticated cooperative projects which make use of the diversity of available channels). The availability of digital media in foreign language learning has already altered fundamental aspects of foreign language teaching and learning (cf. Legutke and Rösler 2005) in the following ways:

- transcending the boundaries of the classroom: teachers and learners can now overcome traditional constraints of classroom learning because digital media provide them with various channels for interacting with speakers of the target language through e-mail, web-conferencing, chat etc.,

- augmenting the traditional textbook: learners, even if they live and learn in places far away from areas in which the target language is spoken, now for the first time ever have unlimited access to a wide range of written, audio or audiovisual target language resources. Above and beyond this they can even play an important role in co-creating a rich and meaningful learning environment by contributing texts and topics according to their needs and interests. Interactive material provides learners with immediate feedback, huge collections of linguistic data provide the opportunity for data-driven learning in a way not previously conceivable,

- empowering the learners: the chance for learners to co-create their learning environment greatly expands their role and shifts responsibility for successful learning to the so-called autonomous learners,

- re-defining teachers' roles: the shift of responsibility to individual learners and small cooperative groups and the use of project formats require a high 
degree of flexibility on the part of the teacher because the learning process is far less predictable. It is therefore not surprising that the discussion of the role of digital media in foreign language learning has led to an intensification of discussions on the role of the teacher generally, and

- offering a greater variety of learning formats: both the new opportunities for learners and teachers to engage in meaningful interaction in foreign language classrooms and the changes in the shape of linguistic material used there has led to a new discussion of learning formats. New ways of focusing on individualized learning have been the result, as well as a questioning of teacher-centered methods and discussions about cooperative learning and project work in which learners take over teaching functions.

These changes will be discussed in the following pages, which will first offer a historical perspective, then go on to sketch the use of media in foreign language learning and teaching over the last century, and finally systematically describe current approaches to computer mediated communication, traditional and intelligent computer assisted language learning, and data-driven learning.

\section{Historical development}

Since the invention of audio recording, foreign language learners could be exposed to spoken language independently of the time when it was spoken; first recordings for foreign language teaching were produced as early as the beginning of the $20^{\text {th }}$ century. With the availability of spoken data on sound storage media it was possible to add an acoustic dimension to textbooks and to provide learners with a linguistic model. For the first time, in theory at least, spoken language could also be learned in self-study with the help of recorded material, and it was also possible to introduce model native speakers and different dialects and sociolects into the classroom to counteract a one-sided orientation of learners towards the linguistic model of the teacher. Learners could imitate the native models and it was also possible, with recording devices, to record learners in their attempts to speak the target language, which enabled a comparison between the model's speech and the learners' realization (cf. Rösler 2010)

With the introduction of language laboratories at the beginning of the 1960s and the associated audio-lingual method, exercises were systematically realized in medial form (cf. Nübold 2006). The main exercises in the language labs were imitation exercises in the form of pattern drills. The undoubted advantages of language labs such as the individualization of practicing and the huge increase of speaking time per learner was accompanied by disadvantages such as the excessive demands on the learners in terms of self-correction, the rigidity of the teaching and learning arrangement and the exclusive focus on form. 
From the 1970s on, parallel to the so-called communicative turn in foreign language teaching and learning, analogue media networks found their way into the classroom. Different analogue media were used simultaneously (cf. Legutke and Müller-Hartmann and Ulrich 2000, 53ff): cassettes, slides, overhead transparencies, films, television. This enabled access to different types of authentic texts, but the disadvantage of these analogue media networks lay, as with the language labs, in the rigidity of the teaching and learning arrangement; teachers felt demoted to media operators who simply had to ensure that predetermined sequences were technically executed (cf. Rösler 2007, 209).

The development of digital media has at least dispelled the technical problems of the analogue media networks. The availability of digital forms of communication and of multimedial material is, however, only a precondition for a new form of learning; they themselves don't actually generate it. Neither an unreflected concept of learner autonomy enabled by the use of digital media (cf. Rösler 1998; Hess 2006 and Schmenk 2008) nor a concept of media use which does not consider the actual interests of the learners (cf. Hess 2003) actually help learners of foreign languages.

The development of foreign language learning with digital media can be sketched as a line of development from simple exercises to complex multimedia learning environments and can be divided into two main areas: Computer Mediated Communication (CMC), in which digital media support and encourage interaction between learners, and Computer Assisted Language Learning (CALL), in which learning material in digitalized form is featured. Terminological confusion is caused by the fact that in some discursive contexts CALL is used as a superordinate for both and in others on the same level as and to demarcate it from CMC. Attempts to systematically define the scope of CMC and CALL have been undertaken by Harrington \& Levy (2001) and others, the development and demarcation of different themes in CALL by Chapelle (2000) and $B a x(2003)$ and others, and there are several descriptions of the historical development of computer-mediated learning (cf. e.g. Chapelle 2001: 1-26; Last 1987; or Levy 1997).

\section{Computer mediated communication}

Plenty of research has been done on CMC in the past decade (cf. e.g. the contributions in O'Dowd 2007 as well as Belz and Thorne 2006). Collaborative work in foreign language learning was not invented with the advent of digital media (cf. the survey in Legutke and Rösler 2005) but the issues discussed before their involvement in foreign language learning have now been enhanced by interesting new perspectives. There are cooperation projects between learners of the same foreign language from different countries, foreign language learners 
and native speakers of the target language, and also between foreign language learners and future foreign language teachers who work as tutors in cooperation projects (cf. Tamme 2001). In addition, the classical project of learning in tandem has become more widespread since digitalization.

\subsection{Transcending the classroom: cooperative projects}

In the same way as in classical cooperation projects where letters, audio or video cassettes were exchanged, questions of contents, general conditions of the institutions involved etc. also determine the success of digital cooperation projects; the availability of particular communication channels alone is not sufficient.

Difficulties related to the composition of groups and the development of social skills, challenging enough in face-to-face learning environments and in predigital cooperative cross-border projects in which both groups basically worked in their own educational contexts and 'merely' exchanged products, can multiply in digital cooperations which combine synchronous and asynchronous cooperation, because intercultural interferences as well as superficially banal constraints such as time-tables can be an additional hindrance to collaboration (on cultural aspects of technical communication see also Sasaki and Lommel 2012 in this volume). Issues such as group assessment and accountability can hit a dead end if the specific interpretations of these concepts differ significantly in the respective cultures of the learners (cf. Müller-Hartmann 2000; Belz and Müller-Hartmann 2003 as well as O'Dowd and Ritter 2006). The discussion of procedural and negotiatory language is traditionally not an essential element in textbooks and frequently not given enough focus in face-to-face cooperative work due to the implicit understanding that the shared frames of the face-to-face group make an elaborate analysis superfluous. It is given heightened attention in CMC collaboration, as complex negotiations through CMC demand a metacommunicative clearing of procedures and modes of negotiation, especially if these are predominantly in written form.

Collaboration via the internet offers a form of intercultural learning which, in the long term, can liberate cultural studies from the circular debate between exemplification and broad survey. Through personal interaction with a partner in one of the countries of the target language, it is possible for learners to experience, in a narrative context, the complexity of another part of the world (cf. Tamme 2001: 128-130).

\subsection{One-to-one cooperation: learning in tandem}

That it has become easier to initiate cooperation since the advent of digital media is shown by correspondence between classes, but especially by the tandem concept (cf. Brammerts and Kleppin 2001) which has developed an exten- 
sive exchange forum in the internet (see http://www.slf.ruhr-uni-bochum.de/). The basic constellation of the tandem has not been changed since its beginnings: people still communicate in mutually agreed forms, each of whom is an expert for their own language, there is still no classical teacher-learner relationship. But the form of exchange has changed, it now takes place through e-mail or via Skype, and possibly even in virtual worlds.

In classical tandem the participants were either in the same place or their exchanges via letters or cassettes took as long as the postal service decreed, the interaction was either synchronous or asynchronous. This 'either-or' has now been eliminated so that partners in different places can choose to communicate synchronously and/or asynchronously. In contrast to learning in the same place, however, there is a loss of the holistic dimension, as neither of the partner's experiences the target language as a space in which they are staying. On the other hand, asynchronic communication such as tandems per e-mail has considerable advantages compared with synchronous communication especially for beginner learners: the partners can take as much time as they need to decode and produce the texts.

\section{Computer-assisted language learning}

CALL augments traditional textbooks by providing learners with access to a wide range of written, audio or audiovisual target language resources. This material is either authentic material not written for didactic purposes or else material specifically produced for learners making use of available technology. Material specifically produced for learners includes podcasts, photos and digital versions of printed material. Two parallel developments exist at the moment, the use of additional digital material to accompany teaching material which is still text book led, and the production of purely digital material. The main attraction of digital material specifically produced for learners lies in its potential interactivity: it can provide them with immediate feedback. The area of CALL most focused upon therefore is the area of tasks and exercises.

\subsection{Digital textbooks}

As far as the provision of additional digital material to textbooks is concerned, there are some obvious improvements:

- there is more room for individualization,

- certain elements of books traditionally not profitable and hence often neglected by publishers (teachers' manuals, glossaries etc), can now be distributed in a more cost-effective and differentiated manner, 
- up-to-date digital add-ons can compensate for the loss of topicality of printed textbooks,

- the space constraints of the traditional textbook which often lead to a shortage of visual and audio-visual information, differentiated sequences of exercises and so on, become less relevant when textbooks can be digitalized.

In the long-term this development can lead to the production of 'textbooks on demand', a new type of textbook which contains a common core element as well as a multitude of digital material tailor-made for the needs of specific learners. Such an approach would recast the traditional textbook as a type of database for which most material could be produced in a decentralized manner around a common core (cf. Rösler 2006).

Soon after the stand-alone exercises at the initial stages of CALL, digital components of textbooks came into being; there is hardly a foreign language textbook which appears today without digital material either in the form of CDs with exercises and tasks or with the provision of online activities. Beyond the closed exercises which focus on form, digital material as a component of textbooks can provide suggestions for projects, material for area studies etc. which are superior to the classical textbooks in terms of potential quantity (extensive collections of visual material, audio and video files) and in terms of topicality; but for this to be an advantage, they have to be produced at the same quality level as the classical printed textbooks.

\subsection{Interactive exercises}

With the advent of the computer came attempts to use it for exercises focusing on form. It was, to some degree, a repetition of the language lab concept (cf. Davies 1997); the learner could address a learning problem more efficiently individualized than in a group of learners. Due to the technology of programming and the authoring software these exercises were initially very limited: fill-in exercises, transformational exercises, drag-and-drop exercises, all of these closed exercises dominated the first round of computer-assisted language learning (cf. Rösler 2007, 104-109). From the point of view of research into teaching foreign language learning, this was a step back behind the diversity of form focused exercise already developed; one could speak, using the name of the most widespread authoring programme, of a Hot-Potatoising of the world of digital exercises.

\subsection{Types and limitations of automatically generated feedback}

A special problem of these exercises is the feedback provided for learners. In contrast to the classical language laboratory which gave the learner a correct answer which he or she could check and repeat, one of the greatest advantages 
of the computer is its interactivity: feedback, response to the learner's input, is possible. The programme has to respond to the learner's input in pre-programmed ways. This feedback is organised within the programme by matching patterns: the learner's input is compared to predetermined patterns, according to the pattern recognized a designated answer follows (cf. Mitschian 1998, 606). In the easiest case the programme generates the message "wrong answer" when the learner does not provide exactly the input anticipated. Whether he or she made a typing error, confused upper with lower case letters or whether it was a serious violation of the rules of the morphology of the target language would not be registered in this case. This type of programming is obviously not didactically satisfactory.

How good or bad automatically generated feedback is depends on how extensive and careful the programmers anticipation is (cf. Nagata 1993, Bangs 2003, Rösler 2007: 177-194). CALL exercises do not have to be as bad as many of those which can be found in the internet: at least with closed exercises the learner's input can be anticipated up to a certain point, careless mistakes can be distinguished from errors in competence and they can receive different feedbacks. The feedbacks can either stimulate self-correction or can provide the correction by referring to sources etc. The most important aspect for ensuring the quality of feedback is the question of how much time and energy was invested in this part of the software which is usually invisible for its users.

With open exercises and tasks, by which the learners have to type their own texts, the programmed analysis fails; all that can be given here as automatically generated feedback are sample solutions, or the texts are sent on to a human corrector who is available online. A new level of quality of feedback can only be achieved if artificial intelligence is introduced into the game and CALL becomes ICALL. This will be discussed later in chapter 6 .

\section{Data-driven learning and teaching}

\subsection{Learning with corpora}

The advent of corpus linguistics introduced new possibilities into foreign language learning (cf. Mukherjee 2008, Beißwenger and Storrer 2009, Granger 2009, Chambers 2010). Its influence appears on two levels. a) Data generated and sorted by corpus linguists enable new insights into the target language for textbook authors and provides them with authentic material for their textbooks. b) Corpus linguistics can be used in the learning process by allowing datadriven learning to play a greater part. While a) obviously increases the potential of foreign language learning, b) is only a useful addition if it is used for the appropriate target groups and learning objects. In the early 1990s Johns and King 
developed corpus-linguistic learning material to motivate learners to contemplate and describe language independently with the help of software and computers. They defined this type of learning as Data-Driven Learning (DDL): "[Data-driven learning is] the use in the classroom of computer-generated concordances to get students to explore regularities of patterning in the target language, and the development of activities and exercises based on concordance output." (Johns and Kings 1991: iii).

The DDL approach aims to introduce learners to the new language they learn by means of corpora so that they are able to discover independently rules and structures of language. This type of learning is opposed to the traditional concept of rule-driven learning, which means that a set of rules is given for a language and variations are not tolerated. Examples are only used to show how grammatical rules work. Strict following of the rules is always the focus, and as a consequence exceptions to the rules are not explained. DDL, in contrast, encourages learners to explore the rules of language themselves. Exceptions to these rules help learners to see that language is not only based on strict rules but that its use always also involves making exceptions. Grammatical rules can always only serve as a benchmark to be followed but they can also be flexed or even broken and sometimes even have to be broken. This is what learners learn from DDL. Some studies, as for example those of Tognini-Bonelli (2001) have shown that this type of learning has a great influence on a learner's motivation.

Several corpus linguists have recognized the impact of DDL and have developed software tools which can be used for integrating corpora into teaching in a rather straightforward manner. A typical example is the Compleat Lexical Tutor (CLT, http://www.lextutor.ca/). CLT offers various functionalities such as vocabulary tests, analyses of mistakes and examinations of concordances which help learners of English, French and German to improve their language skills. Besides such web tools concordance programmes have been developed, e.g. the WordSmith Tools (http://www.lexically.net/wordsmith/), and have been designed in a more user-friendly way during the last years. As a rule of thumb it can be said that the more advanced learners are the more useful the application of DDL becomes. Advanced learners, for instance, can profit considerably from corpora while trying to engage with complex lexical phenomena such as collocations (cf. Ludewig 2005).

\subsection{Learner corpora}

A learner corpus is a huge computer-generated collection of written or oral texts produced by learners of a foreign language which can be automatically analyzed just like any other corpus. In contrast to first language corpora (cf. Lüdeling and Kytö 2008) learner corpora are set up in a more systematic way: mostly external criteria like first language background, foreign language competence, level of 
competence, learning setting, sex, age etc. determine the choice of texts and participants. Each of these external criteria can be analyzed individually or as a group, the analysis can thus yield results on the specific characteristics in foreign language learning. In the field of corpus linguistics, learner corpora represent a relatively new development. The first learner corpora were compiled in the late eighties. The most and the biggest learner corpora exist for English as a target language. In comparison, the number of freely accessible learner corpora for the German language is small (cf. Lüdeling et al. 2008).

Learner corpora give insights into non-native speakers' characteristics of language production. Thus, they are relevant for theories of second language acquisition and learning as well as for the development of teaching materials and instruction materials. Based on findings from learner corpora, exercises for individual groups of learner can be developed (cf. Seidlhofer 2002: 214).

In its initial stages learner corpora analysis was dominated by a descriptive linguistic view comparing language production of learners with corpus data of native speakers to identify characteristics of learner language. Typical questions asked by this approach are the following: Which kind of structures does the learner use too often (overuse), too rarely (underuse) or wrongly (misuse)? Are there any structures in the learner's language which do not find a similar use either in the structure of the target language or in the structure of the native language (learner-idiosyncratic structures)? In which area do learners tend to use an avoidance strategy, where do they not exploit the full potential of the target language?

However, new types of corpus projects make it possible to define core areas where learner with a specific first language $(=\mathrm{L} 1)$ and learners with varying first languages (Lx) do not behave appropriately in the target language. The first one gives insights into the interferences caused by features of the learner's native language whereas the latter, by comparing interlanguage use of learners with different native languages, gives insights into the complexity of learning certain structures in the target language (cf. Granger 2002). Examples of this kind of corpora are the International Corpus of Learner English (ICLE: 50 Subcorpora, learner language with different native language, target language English, written text, cf. Nesselhauf 2004) and the Louvain International Database of Spoken English Interlanguage (LINDSEI: 50 Subcorpora, Learner language with different native languages, target language English, spoken texts).

The use of findings from learner corpora analysis is only slowly integrated into the development of teaching material. When comparing the learner language with different native language backgrounds it can be shown that a great number of mistakes is based on interference from Ll or other acquired languages (cf. Hufeisen 1990) and has no universal character. Thus one will find the same grammatical/lexical phenomenon of a foreign language strongly depending on the learner's native or previously acquired language(s). Based on 
this, individual teaching materials and instructional materials should be developed which focus on problems and move away from a prototypical notion of the learner (cf. Granger 1998, Seidlhofer 2002).

\section{Intelligent computer assisted language learning}

\subsection{CALL and ICALL}

The term Computer-assisted Language Learning (CALL) is not always used consistently throughout literature (see the end of chapter 2). It is often used as a generic term for traditional CALL-systems as well as for Intelligent CALL (ICALL) systems. According to Levy (1997) CALL could, in general, be defined as "the search for and the study of applications of the computer in language teaching and learning. [...] The subject is interdisciplinary in nature and it has evolved out of early efforts to find ways of using the computer for teaching or for instructional purposes across a wide variety of subject areas, with the weight of knowledge and breadth of application in language learning ultimately resulting in a more specialized field of study." (Levy 1997: 1). Thus CALL can be described as a special concept of language learning.

Warschauer (1996) distinguishes three phases of CALL: Behaviour-related CALL, based on behaviour-related learning theory, Communicative CALL, based on communication-related learning theory, and Integrative CALL, which is based on two technological developments, namely multimedia and internet. Traditional applications are based on a behaviouristic learning theory. They involve only closed exercises, e.g. Multiple Choice Exercises, click exercises and texts with gaps. Those systems consist mainly of the following steps: First there is a short introduction to the topic at the beginning of each exercise where factual knowledge is given. Then the factual knowledge is supposed to be learned with drill-and-practice exercises. Here, the learner is given positive feedback when the answer is correct, but there, no feedback at all is given to wrong answers. Such drilling programs can be developed with little programming effort. While this is an advantage to the person developing such a program, it turns out to be monotonous and boring for the learner working with it. Besides CALL applications there are many ICALL-systems which have been designed according to behaviour-related principles and use only closed exercises.

In contrast to behaviourist exercises, detailed feedback plays an important role in cognitive theory which is supposed to help the learner to deduce rules independently, notice learning problems and to reflect on learning processes. Furthermore cognitive teaching material is supposed to support independent learning, for instance concerning the choice of the level of difficulty, the way of looking at a problem, and the learning speed. Cognitive theories are imple- 
mented by Intelligent Tutoring Systems. Here, the computer takes the role of a tutor. The systems are supposed to be intelligent because they arrange the learning material in a flexible way and because they adapt to the level of knowledge and cognitive performance of the learner (cf. Schulmeister 2002: 187). However, it has to be pointed out that the implementation of such application is rather complex, so that it often did not develop beyond a prototype. Furthermore most systems are a long way from adequately imitating cognitive characteristics of information processing.

In the constructive approach, the learning material is embedded in a simulated real-life interaction to enable learners to generate relevant strategies of dealing with a communicative problem by themselves. Here the teacher functions as a coach, who - according to the situation - explains a process or demonstrates a pattern of behaviour, introduces the learners to the problem, but finally fades out and accompanies the learner during the process.

\subsection{Approaches to ICALL systems}

The development of CALL has been strongly influenced by upcoming new technologies during the past few years. This has lead to a general criticism of ICALL projects being too technology driven at the expense of didactics. This criticism has been reinforced by classifications which reflect those technical aspects. Wolff (1993: 21) distinguished five groups of applications:

- Traditional CALL applications: programs of the initial phase of CALL based on behaviour-related learning theory.

- Multimedia-based applications: combining text with visual and audio devices.

- Tools and backup systems (utilities): applications which have not especially been developed for foreign language learning such as monolingual or bilingual dictionaries, spell checkers, word processing programs etc.

- Artificial Intelligence applications: consisting of formalized knowledge on the subject or on the user (see Kopp and Wachsmuth 2012 in this volume on artificial intelligence in artificial interactivity).

- Communicative applications: These can be summarized by the term "computer-mediated communication" (see above, chapter 3 ).

It is important to mention that most available systems show different characteristics. In the following only Artificial Intelligence (AI, cf. Luger 2008) applications will be considered because only they use Natural Language Processing (NLP, cf. Clark et al. 2010) for approaching the learner's usage of language. Such a CALL application implies for example grammar knowledge about the target language, domain knowledge or knowledge about the user to adapt individually to the necessities of each single user. Even though these systems could be more communicatively complex, they often invoke the same learner activ- 
ities as traditional CALL applications. An advantage of this type of system is its intelligent behaviour with regard to the learner input, which offers sophisticated feedback.

The term "parser-based CALL" does not only better match the special field than the expression "intelligent CALL". It also indicates the application of language technology in CALL as a possible approach beside others (cf. Heift and Schulze 2007: 2). Numerous applications for different languages have been developed during the now 40-year history of ICALL - unfortunately very often not going beyond the experimental stage (for an overview see Amaral and Meurers 2006). As it would be impossible to enumerate all these systems, three applications for the German language will be considered below.

\section{Bridge German Tutor}

The Bridge German Tutor (Holland, Kaplan, and Sams 1995; Kreyer and Criswell 1995; Sams 1995; Weinberg et al. 1995) was developed at the Army Research Institute (ARI). The system utilizes a robust shift-reduce-parser (cf. Weinberg et al. 1995) that can be upgraded by the system administrator. It offers detailed feedback to the learner input and manages simultaneously a student model with the learner's weak and strong sides which can be used for supervising the progress (cf. Sams 1995). The Bridge Tutor realizes different types of exercises. In order to give feedback to the learner, gap-filling exercises and free text production exercises are analyzed by the natural language processing modules. Grammar mistakes are identified and classified as primary and secondary mistakes. This categorization can be influenced by the authors of the exercises. The exercises are tailored in such a way that they take the parser's limits into consideration but take advantage of its full potential. The exercises can be composed by means of an authoring system, and no specific programming skills are needed for its use. The exercises can then either be solved one after the other according to the progress or be chosen from an exercise pool.

\section{ALLES}

ALLES (Advanced Long-distance Learning Education System, EU project 2002-2005, http://alles.atosorigin.es) is a multimedia-based language learning system that was developed for the advanced independent learner of level B2 to $\mathrm{C} 1$ of the Common European Framework of Reference for Languages. The following skills can be trained for English, German, Spanish and Catalan:

- listening comprehension,

- reading comprehension and

- writing skills. 
The exercises imply a monotonous series of MC-exercises and gap-filling texts and partly open types of exercises which expect a free text input. Here, short questions have to be answered, sentences to be paraphrased and free texts such as e-mails and memos to be written under strong constraints. This kind of control is supposed to provide for a content-related feedback. It is checked whether important concepts have been kept in the right order in the answer. This feedback, however, is based on given phrases which have to be applied exactly in the same way in the text. If a phrase cannot be found, it will be suggested that the given content-related item is to be mentioned in the text. All gap-filling exercises (free text input counts as gap-filling, too) are first checked orthographically during the analysis. For spelling mistakes proposals of correction are presented, if possible. Finally, the input is analyzed with the morphological parser MPRO ("Morphology PROgram"). This natural-language analysis offers appropriate feedback for declination, conjugation and for wrong commas in infinitive constructions. The feedback for syntax errors is based on given pattern solutions, so missing or useless words or those in a wrong position are found with the help of a simple pattern-matching device. If a single mistake causes several mistakes, messages about those are not collected and summarized but are passed on directly to the learner - this manner of correction can be very confusing for users.

\section{Deutsch-Uni online (DUO)}

DUO, the "Deutsch-Uni online" (http://www.iai.uni-sb.de/iaide/de/uni_deutsch. htm) (cf. Roche 2008) is a complex communicative learning setting. It offers online courses for all levels with different focuses. The courses imply interactive instruction material which can be accompanied by tutor-oriented assistance (assisted learning), if desired. Furthermore, DUO offers possibilities for working in groups together in virtual classes and enables contacts to other learners in the whole world. Exercises imply the following forms of interaction: Marking of text parts, drag-and-drop exercises, MC-exercises (simple choice, multichoice) yes/no-questions with input of right solutions) gap-filling text (traditional with drop-down-list, paraphrase), crossword puzzle, word guessing (European mandrake), matching exercises, and audio tapes. The program implies an "intelligent electronic assistant" who executes grammatical analysis on the syntactical level and gives hints to the learner for correction. The analysis is based on the MPRO system of the IAI Saarbrücken. Furthermore additional helping tools (as for example a learning dictionary and a concordance module) and media communication are integrated in the learning setting. 


\section{Conclusion and prospect of future developments}

Given the relatively short time span which has been available for the development so far, it is impressive to see to what extent digital media has already been integrated into foreign language learning. From the early stand-alone exercise emerged the multimedia learning environment accompanying and sometimes replacing traditional textbooks. Early computer mediated communication via email developed into sophisticated types of interaction via conference software, communal learning environments and the whole range of social software (cf. Chaudhuri and Puskas 2011). First studies on the integration of virtual environments like Second Life, in which learners meet in the form of their avatars, show how the various means of communication can be made functional for different learning purposes, e.g. while voice chat is used for direct 'face to face' communication, the accompanying text chat is used simultaneously for meta-communicative messages (cf. Biebighäuser and MarquesSchäfer 2009).

Looking into the future, one could imagine an integration of CALL and CMC as sketched in Rösler 2000: virtual worlds becoming so sophisticated that learners don't just meet other learners in the form of avatars, but encounter other figures which/who, having passed the Touring test, can neither be identified as other people's avatars nor as artificial scripted figures. Learners would then simply interact naturally with other figures who adapt, in the interaction, to the learners' level of linguistic and cultural knowledge: the learner's perspective would be that of one in the process of natural foreign language acquisition, but it would take place in a very complex artificial learning environment which anticipates learners' moves far beyond what is currently available as simulations for foreign language learning.

\section{Note}

1. Some parts of this paper are based on state-of-the-art reports provided by Susanne Kämmerer, Csilla Puskas and Sven Saage. The authors would like to thank them for this valuable support.

\section{References}

Amaral, Luiz and Detmar Meurers

2006 Where does ICALL Fit into Foreign Language Teaching? 23rd Annual Conference of the Computer Assisted Language Instruction Consortium (CALICO), May 19, Honolulu, University of Hawaii [URL http://purl.org/ net/icall/handouts/calico06-amaral-meurers.pdf]. 
Bangs, Paul

2003 Engaging the learner - how to author for best feedback. In: Uschi Felix (ed.), Language learning online: Towards best practice, 81-96. Lisse: Sweets \& Zeitlinger.

Bax, Stephen

2003 CALL - past, present and future. System 31, 1/03: 13-28.

Beißwenger, Michael and Angelika Storrer

2008 Corpora of Computer-Mediated Communication. In: Anke Lüdeling and Merja Kytö (eds.), Corpus Linguistics. An International Handbook. Volume 1, 292-308. (Handbooks of Linguistics and Communication Science 29.1.) Berlin/New York: De Gruyter.

Belz, Julie A. and Andreas Müller-Hartmann

2003 Teachers as Intercultural Learners. Negotiating German-American Telecollaboration along the Institutional Fault Line. The Modern Language Journal 87, 1: 71-89.

Belz, Julie A. and Steven L. Thorne (eds.)

2005 Internet-Mediated Intercultural Foreign Language Education. Boston: Thomson Heinle.

Biebighäuser, Karin and Gabriela Marques-Schäfer

2009 Text-Chat und Voice-Chat beim DaF-Lernen online: Eine empirische Analyse anhand der Chatangebote des Goethe-Instituts in JETZT Deutsch lernen und in Second Life. Info DaF 36, 5: 411-428.

Brammerts, Helmut and Karin Kleppin (eds.)

2001 Selbstgesteuertes Sprachenlernen im Tandem. Ein Handbuch. Tübingen: Stauffenburg.

Chambers, Angela

2010 What is data-driven learning? In: Anne O'Keffee and Michael McCarthy (eds.), The Routledge Handbook of Corpus Linguistics, 345-358. London: Routledge.

Chapelle, Carol A.

2000 Is network-based learning CALL? In: Mark Warschauer and Richard Kern (eds.), Network-based language teaching: Concepts and practice, 204-228. Cambridge: Cambridge University Press.

Chapelle, Carol A.

2001 Computer applications in second language acquisition. Cambridge: Cambridge University Press.

Chaudhuri, Tushar and Csilla Puskás

2011 Interkulturelle Lernaktivitäten im Zeitalter des Web 2.0. Erkenntnisse eines telekollaborativen Projektes zwischen der Hong Kong Baptist University und der Justus-Liebig-Universität Gießen. In: Info DaF 38, 1: 3-25.

Clark, Alexander, Chris Fox and Shalom Lappin (eds.)

2010 The Handbook of Computational Linguistics and Natural Language Processing (Blackwell Handbooks in Linguistics 57.) Oxford: Wiley-Blackwell.

Davies, Graham

1997 Lessons from the past, lessons for the future. 20 years of CALL. In: Dieter Kranz, Lienhard Legenhausen and Bernd Lücking (eds.), Multimedia Internet-Lernsoftware, 111-130. Münster: agenda Verlag. 
Granger, Sylvaine

1998 The computer learner corpus: a versatile new source of data for SLA research. In: Sylvaine Granger (eds.), Learner English on Computer, 3-8. London: Longman.

Granger, Sylvaine

2002 A bird's-eye view of computer learner corpus research. In: Sylvaine Granger, Joseph Hung and Stephanie Petch-Tyson (eds.), Computer Learner Corpora, Second Language Acquisition and Foreign Language Teaching, 3-33. Amsterdam/Philadelphia: John Benjamins.

Granger, Sylviane

2009 Learner Corpora. In: Anke Lüdeling and Merja Kytö (eds.), Corpus Linguistics. An International Handbook. Vol. 1, 259-275. (Handbooks of Linguistics and Communication Science.) Berlin/New York: De Gruyter.

Harrington, Michael and Mike Levy

2001 CALL begins with a ' $C$ ': interaction in computer-mediated language learning. System 29: 15-26.

Heift, Trude and Mathias Schulze

2007 Errors and Intelligence in Computer-Assisted Language Learning. Parsers and Pedagogues. New York/London: Routledge.

Hess, Hans-Werner

2003 Lerner als Kunden. Informationstechnologie im Alltagseinsatz [Learners as Customers. Applied Information Technology]. Deutsch als Fremdsprache 40, 1: 14-23.

Hess, Hans-Werner

2006 Beyond the Rhetoric of the 'Autonomous Learner': Combining E-Learning and the Classroom. Electronic Journal of Foreign Language Teaching 3, 1: 102-120.

Holland, Melissa V., Jonathan D. Kaplan and Michelle R. Sams (eds.)

1995 Intelligent Language Tutors: Theory Shaping Technology. New Jersey: Lawrence Erlbaum Associates.

Johns, Tim and Philip King

1991 Classroom Concordancing. Birmingham: University of Birmingham.

Kopp, Stefan and Ipke Wachsmuth

2012 Artificial interactivity. In: Alexander Mehler, Laurent Romary and Dafydd Gibbon (eds.): Handbook of Technical Communication. Berlin/Boston: De Gruyter.

Kreyer, Steve and Eleanor Criswell

1995 Instructor as Author in an Adaptive, Multimedia, Foreign Language Tutor. In: Melissa V. Holland, Jonathan D. Kaplan and Michelle R. Sams (eds.), Intelligent Language Tutors: Theory Shaping Technology, 45-53. Mahwah/ New Jersey: Lawrence Erlbaum.

Last, Rex W.

1989 Artificial intelligence techniques in language learning. Chichester: Horwood.

Legutke, Michael and Dietmar Rösler

2005 Enhancing collaborative work by integrating digital media into foreign language teacher education. Fremdsprachen lehren und lernen 34: 174-191. 
Legutke, Michael, Andreas Müller-Hartmann and Stefan Ulrich

2000 Neue Kommunikationsformen im fremdsprachlichen Unterricht. In: Gerd Fritz and Anderas Jucker (eds.), Kommunikationsformen im Wandel der Zeit, 51-73. Tübingen: Niemeyer.

Levy, Michael

1997 Computer-Assisted Language Learning. Context and Conceptualisation. Oxford: Clarendon Press.

Lüdeling, Anke, Seanna Doolittle, Hagen Hirschmann, Karin Schmidt and Maik Walter 2008 Das Lernerkorpus Falko. Deutsch als Fremdsprache 2, 45: 67-73.

Lüdeling, Anke and Merja Kytö (eds.) 2008/2009 Corpus Linguistics. An International Handbook. Volume 1/2. (Handbooks of Linguistics and Communication Science.) Berlin/New York: De Gruyter.

Ludewig, Petra

2005 Korpusbasiertes Kollokationslernen: Computer-Assisted Language Learning als prototypisches Anwendungsszenario der Computerlinguistik. (Computer Studies in Language and Speech 9.) Frankfurt-Main/Berlin: Peter Lang.

Mitschian, Haymo

1998 Von Mitteln und Mittlern. Zur Rolle des Computers beim Fremdsprachenlernen. Info DaF 25, 5: 590-613.

Mukherjee, Joybrato

2008 Anglistische Korpuslinguistik und Fremdsprachenforschung: Entwicklungslinien und Perspektiven. Zeitschrift für Fremdsprachenforschung 19, 1: 31-60.

Müller-Hartmann, Andreas

2000 "Wenn sich die Lehrenden nicht verstehen, wie sollen sich dann die Lernenden verstehen?" Fragen nach der Rolle der Lehrenden in global vernetzten Klassenräumen. In: Lothar Bredella, Herbert Christ and Michael K. Legutke (eds.), Fremdverstehen zwischen Theorie und Praxis, Arbeiten aus dem Graduierten-Kolleg "Didaktik des Fremdverstehens", 275-301. Tübingen: Narr.

Nagata, Noriko

1993 Intelligent computer feedback for second language instruction. The Modern Language Journal 77, iii: 330-339.

Nesselhauf, Nadja

2004 Learner Corpora and their potential for language teaching. In: John Sinclair (ed.), How to Use Corpora in Language Teaching, 125-152. Amsterdam/ Philadelphia: John Benjamins.

Nübold, Peter

2006 Vom Sprachlabor zum Multimedia-Sprachlabor. In: Udo O.H. Jung (ed.), Praktische Handreichungen für Fremdsprachenlehrer, 299-304. Frankfurt am Main: Peter Lang, 4. edition.

O'Dowd, Robert (ed.)

2007 Online Intercultural Exchange. An Introduction for Foreign Language Teachers. Clevedon/Buffalo/Toronto: Multilingual Matters. 
O'Dowd, Robert and Markus Ritter

2006 Understanding and Working with 'Failed Communication' in Telecollaborative Exchanges. CALICO Journal 23, 3: 1-20.

Roche, Jörg

2008 Handbuch Mediendidaktik. Ismaning: Hueber.

Rösler, Dietmar

1998 Autonomes Lernen? Neue Medien und 'altes' Fremdsprachenlernen. Info DaF 25, 1: 3-20.

Rösler, Dietmar

2000 Fremdsprachenlernen außerhalb des zielsprachigen Raums per virtueller Realität. In: Gerd Fritz and Andreas Jucker (eds.), Kommunikationsformen im Wandel der Zeit, 121-135. Tübingen: Niemeyer.

Rösler, Dietmar

2006 Zwischen Lehrwerk und Online-Sprachbad. Zur Neubestimmung von Funktion und Gestalt von Lehrmaterialien im Anfängerunterricht. In: Hans-Jürger Krumm and Paul Portmann-Tselikas (eds.), Theorie und Praxis. Österreichische Beiträge zu Deutsch als Fremdsprache, 143-154. Innsbruck: Studien-Verlag.

Rösler, Dietmar

2007 E-Learning Fremdsprachen - eine kritische Einführung. Tübingen: Stauffenburg, 2nd edition.

Rösler, Dietmar

2010 Die Funktion von Medien im Deutsch als Fremd- und Deutsch als Zweitsprache-Unterricht. In: Hans-Jürgen Krumm, Christian Fandrych, Britta Hufeisen and Claudia Riemer (eds.), Deutsch als Fremd- und Zweitsprache. Ein internationales Handbuch, 1199-1214 (Handbooks of Linguistics and Communication Science 35/2). Berlin/New York: de Gruyter Mouton.

Sams, Michelle R.

1995 Advanced Technologies for Language Learning: The BRIDGE Project Within the ARI Language Tutor Programm. In: Melissa V. Holland, Jonathan D. Kaplan and Michelle R. Sams (eds.), Intelligent Language Tutors: Theory Shaping Technology, 7-21. Mahwah/New Jersey: Lawrence Erlbaum.

Sasaki, Felix and Arle Lommel

2012 Multilingual computing. In: Alexander Mehler, Laurent Romary and Dafydd Gibbon (Eds.): Handbook of Technical Communication. Berlin/Boston: de Gruyter.

Schmenk, Barbara

2008 Lernerautonomie: Karriere und Sloganisierung des Autonomiebegriffs. Tübingen: Narr.

Schulmeister, Rolf

2002 Grundlagen hypermedialer Lernsysteme: Theorie - Didaktik - Design. München: Oldenbourg, 3. edition.

Seidlhofer, Barbara

2002 Pedagogy and local learner corpora: working with learning-driven data. In: Sylviane Granger, Joseph Hung and Stephanie Petch-Tyson (eds.), Computer Learner Corpora, Second Language Acquisition and Foreign Language Teaching, 214-234. Amsterdam/Philadelphia: John Benjamins. 
Tamme, Claudia

2001 E-Mail-Tutorien: eine empirische Untersuchung E-Mail-vermittelter Kommunikationen von Deutschstudierenden und Deutsch-als-FremdspracheLehrenden in der Ausbildung. Online: http://geb.uni-iessen.de/geb/volltexte/2003/1009/ (16.6. 10).

Tognini-Bonelli, Elena

2001 Corpus Linguistics at Work. (Studies in Corpus Linguistics 6.) Amsterdam: John Benjamins B.V.

Warschauer, Mark

1996 Computer-Assisted Language Learning: An Introduction. In: Sandra Fotos (eds.), Multimedia Language Teaching, 3-20. Tokyo: Logos International. Weinberg, Amy, Jeffery Garman, Joe Martin and Paola Merlo

1995 A Principle-Based Parser for Foreign Language Tutoring in German and Arabic. In: Melissa V. Holland, Jonathan D. Kaplan and Michelle R. Sams (ed.), Intelligent Language Tutors: Theory Shaping Technology, 23-43. Mahwah/New Jersey: Lawrence Erlbaum.

Wolff, Dieter

1993 New Technologies for Foreign Language Teaching. In: Foreign Language Learning and the Use of New Technologies. Conference Proceedings. London 1993. Brussels: Bureau Lingua. 